九州大学学術情報リポジトリ

Kyushu University Institutional Repository

Hydro-conversion of 1-methyl naphthalene into (alkyl)benzenes over alumina-coated USY zeolite-supported NiMoS catalysts

Park, Joo-Il

Institute for Materials Chemistry and Engineering, Kyushu University

Lee, Jihn-Koo

121 Bio-venture Center, Korea Research Institute of Bioscience and Biotechnology

Miyawaki, Jin

Institute for Materials Chemistry and Engineering, Kyushu University

Kim, Young-Kwang

Institute for Materials Chemistry and Engineering, Kyushu University

他

http://hdl. handle. net/2324/25442

出版情報：Fuel.90（1），pp. 182-189，2011-01-01. Elsevier バージョン：

権利関係: (C) 2010 Elsevier Ltd. 


\title{
Hydro-conversion of 1-methyl naphthalene into (alkyl)benzenes over alumina-coated USY zeolite-supported NiMoS catalysts
}

\author{
Joo-Il Park ${ }^{\mathrm{a}}$, Jihn-Koo Lee ${ }^{\mathrm{b}}$, Jin Miyawaki ${ }^{\mathrm{a}}$, Young-Kwang Kimª, \\ Seong-Ho Yoon ${ }^{\mathrm{a} *}$ and Isao Mochida ${ }^{\mathrm{a}}$
}

${ }^{a}$ Institute for Materials Chemistry and Engineering, Kyushu University,

Fukuoka 816-8580, Japan

${ }^{\mathrm{b}} 121$ Bio-venture Center, Korea Research Institute of Bioscience and Biotechnology, 52 Eoun-dong, Yuseong-gu, Daejeon 305-806, Republic of Korea

Tel.: +81-92-583-7959, FAX : + +81-92-583-7897

e-mail : yoon@cm.kyushu-u.ac.jp 


\section{Abstract}

Hydro-conversion reactions were carried out at $360^{\circ} \mathrm{C}$ under $5 \mathrm{MPa}$ of $\mathrm{H}_{2}$ pressure to study ring-opening reactions of 1-methyl naphthalene using NiMoS supported on $\gamma$-alumina and alumina-coated/mixed USY zeolites. The catalysts were characterized using $\mathrm{N}_{2}$-BET, X-ray diffraction (XRD), X-ray photoelectron spectroscopy (XPS), pyridine FT-IR, and high-resolution transmission electron microscopy (HRTEM) to study the influence of morphological and acidic properties on hydrogenation (HYD) and hydrocracking (HC) reactions. NMACZ-2 (NiMoS supported on the minimum amount of alumina-coated USY zeolite) showed enhanced reactivity for $\mathrm{HC}$ and produced (alkyl)benzenes with the highest yield, of ca. $80 \%$. By-products were tetralin, decalin and cyclo-paraffin species. The tetralin species produced using NMACZ-2 moved into the alumina-coated USY zeolite support before undergoing HYD to produce decalin species, which were rapidly and selectively hydro-cracked into (alkyl)benzenes. A large amount of decalin was produced through the HYD of tetralin without significant cracking, possibly due to the weak acid character of $\gamma$-alumina. Bulk-phase Mo oxide species on NMAZ (physical mixture of alumina and USY zeolite), as well as deactivation of the catalysts due to coke formation over the naked zeolite surface, inhibited the ring opening of tetralin, decreasing the yield of (alkyl) benzene. 
Various morphologies, such as the $\mathrm{MoS}_{2}$ structure and acidic characteristics of the catalysts, were crucial factors affecting the $\mathrm{HC}$ reactivity of 1-methyl naphthalene.

Keywords: LCO, (Alkyl)benzenes, Alumina coated zeolite, 1-methyl naphthalene 


\section{Introduction}

Light cycle oil (LCO), composed of two- and three-aromatic ring compounds, is produced in large scale through the popular FCC process. LCO is used as a blend-stock in heavy fuel oil for viscosity adjustment [1]. Its value-added uses in diesel fuel and aromatic chemical feed are required to meet increasing demands [2, 3]. Generally, considerable ignition delays, expressed as low cetane number, lead to rough engine operation, misfiring, incomplete combustion, and poor stability. To improve the cetane number for diesel fuel or to produce BTX (benzene, toluene, and xylene) for a useful aromatic chemical feed, one aromatic ring must be selectively preserved to form one phenyl ring with alkyl chains. Selective HYD and HC are common ring-opening reactions used for effective conversion of the aromatic ring to the phenyl ring. The LCO-X process (UOP LLC) was commercialized as a hydrotreatment in which aromatic rings of LCO are fully hydrogenated by noble metal catalysts, and the hydrogenated rings are cracked using a zeolite. It is difficult to achieve selective conversion, and significant amounts of hydrogen are consumed. Thus, an effective ring opening of polycyclic aromatics in LCO, and subsequent conversion into (alkyl)benzenes through selective hydro-conversion over novel or improved catalysts, is desirable.

Much research has focused on developing more effective catalysts for improved 
performance with HYD and HC ring-opening reactions. A catalyst with an active phase of Ni-Mo-P supported on mixed alumina and zeolite was used for HYD and HC of mixed diaromatics and alkyl-tetralin to produce alkylbenzenes (denoted as monoaromatics in this paper) at $400^{\circ} \mathrm{C}(1 \mathrm{~h}-1$ of LHSV) under 28 atm [1]. Tomita et al. suggested that metal-free ultra-stable Y (USY) zeolite was favored for HC of various aromatic hydrocarbons into BTX, and the authors suggested a possible reaction mechanism [4,5]. The effectiveness of USY, amorphous silica-alumina (ASA) and ITQ2 zeolite was also tested for HYD and HC of hydro-treated LCO, and the highest reduction in total aromatics over Pt supported on an ITQ-2 catalyst was reported. However, hydro-conversion into (alkyl)benzenes was more effective using the USY zeolite-supported Pt catalyst [6]. HC of LCO was also investigated with decalin and tetralin as probe molecules using zeolites with medium, large, and ultra-large micropores, as well as mesopores [7]. The influence of pore diffusion on ring-opening, dealkylation, transalkylation, hydrogen transfer, and coke formation reactions was explained. Corma et al. claimed that the Y zeolite was most suitable for the effective hydro-conversion of LCO because of its pore structure and acidity.

Recently, Liu et al. studied the selective ring opening of naphthalene using a $\mathrm{Mo} 2 \mathrm{C} / \mathrm{HY}$ catalyst [8]. They reported that the increased reactivity of $\mathrm{Mo}_{2} \mathrm{C} / \mathrm{HY}$ was not 
readily obtained through a simple mechanical mixture of bulk $\mathrm{Mo}_{2} \mathrm{C}$ and $\mathrm{HY}$. However, increased amounts of $\mathrm{Mo}_{2} \mathrm{C}$ decreased the number and strength of acid sites, especially Brönsted acid sites, which are necessary for selective ring opening to derive the carbon deposition, and deactivate the catalytic reactivity. Support materials with unique pore characteristics were applied to the HYD and HC catalysts [9-13]. As mentioned above, although new catalysts were selected and applied, the conventional $\mathrm{Ni}-\mathrm{Mo}(\mathrm{W}) /\left[\mathrm{Al}_{2} \mathrm{O}_{3}\right.$ or zeolite] catalysts are still the most widely used for selective ring opening.

The aim of this work was to improve the yield of (alkyl)benzenes through effective hydro-conversion of hydro-treated (HDS and HDN) LCO. High sulfur and poly-aromatic contents in LCO must be reduced to meet the current standards for diesel fuel. Such reductions can affect the cetane value and the combustion characteristics of the products. Thus, the suitable catalyst for effective ring opening of polycyclic aromatic rings to (alkyl)benzenes should be able to simultaneously enhance the HDS of feed oil. In previous work, various kinds of alumina or surface-modified zeolite supported transition metal catalysts, alone or in combination, were surveyed for HDS and HDN on various feeds [14-21]. We found that the alumina-coated zeolite-supported Ni-Mo catalyst (NMACZ) series showed the highest reactivity. In this paper, we used 1methylnaphthalene as a model material for LCO and examined the reactivity of HYD 
and $\mathrm{HC}$ for selective ring-opening reactions over NMACZ catalysts.

To aid in following the acronyms in this paper, a list of abbreviations can be found in the appendix. 


\section{Experimental}

\subsection{Catalysts}

NiMo catalysts supported on $\gamma$-alumina (NMA), a physical mixture of alumina and USY-zeolite (Si/Al of zeolite: 30, USY zeolite contents: 50\%, NMAZ), and USY zeolites modified with various amounts of coated alumina (USY-zeolite content: 50\%, NMACZ1 and NMACZ2, - (10), - (20), - (40)) were supplied from CCIC, Japan. The loading amounts of nickel and molybdenum oxide were controlled at 5 and $20 \mathrm{wt} \%$, respectively, for each catalyst.

USY zeolite was prepared from a NaY precursor by a typical method. Alumina in $\mathrm{NaY}$ was extracted using acid to obtain high silica/alumina ratios in the zeolite network for a suitable solid acidity and hydrothermal stability.

The coated USY zeolites (ACZ-1 and ACZ-2) were prepared by coating porous aluminum hydroxide on the USY zeolite using a neutralization procedure. The coating amount was controlled as necessary. The coated material was converted into alumina on the surface of USY zeolite using continuous calcination. Three different amounts of alumina between ACZ-1 and ACZ-2 were prepared and are referred to as ACZ-2 (10), ACZ-2 (20) and ACZ-2 (40). 


\subsection{Hydro-conversion reaction}

1-Methyl naphthalene was used as a model material for this study. A solution of $10 \mathrm{wt} \%$ 1-methylnaphthalene (ca. $3.3 \mathrm{~g}$ ) in dodecane (30 g) was hydrogenated and hydrocracked over sulfided catalysts at $360^{\circ} \mathrm{C}$ for $2 \mathrm{~h}$ under $\mathrm{H}_{2} \mathrm{~S}(5 \mathrm{vol} \%)$ and hydrogen (balanced vol\%) flow prior to the reaction. Hydro-conversion was carried out using an autoclave reactor $(150 \mathrm{~mL})$ equipped with a sampling port containing the sulfided catalyst $(10 \mathrm{wt} \%$, ca. $3.7 \mathrm{~g})$ at $360^{\circ} \mathrm{C}$ for $6 \mathrm{~h}$ under a starting pressure of $5 \mathrm{MPa}$ of $\mathrm{H}_{2}$.

\subsection{Analysis of Products}

Carbon species were analyzed before and after reactions using gas chromatography coupled with an atomic emission detector (GC-AED, GC: Agilent 6890N, AED: G2350 A) and GC-MS (HP6890/5973). The dual identification of GCAED (quantitative analysis) and GC-MS (qualitative analysis) allowed detailed analysis of the carbon species $[22,23]$. The conditions for analyses are summarized in Table 1.

\subsection{Characterization of catalysts}

The physical characteristics of the as-received catalysts, such as surface area, pore volume and pore size, were evaluated using $\mathrm{N}_{2}$ BET at $77 \mathrm{~K}$, measured with a BELSORP-Max-S (Nippon BEL Inc. Japan). Prior to the measurements, catalysts were degassed at $150^{\circ} \mathrm{C}$ for $10 \mathrm{~h}$. 
The crystallographic characteristics of the catalysts were evaluated using X-ray diffraction (Rigaku UltimaIII, CuK $\alpha$ target, Rigaku, Japan). Data were collected using a continuous scan mode with a 2 -theta range of $5^{\circ}$ to $70^{\circ}$ and a scan rate of $2 \% \mathrm{~min}$.

Catalyst surfaces were characterized using X-ray photoelectron spectroscopy (XPS, JEOL) under a vacuum of less than $4 \times 10^{-7}$ Torr with a non-chromatized $\mathrm{Mg} \mathrm{K \alpha}$ $\mathrm{X}$-ray at $1253.6 \mathrm{eV}(10 \mathrm{kV}, 10 \mathrm{~mA})$. High-resolution $\mathrm{C} 1 \mathrm{~s}$ spectra of the adventitious hydrocarbons (at $284.5 \mathrm{eV}$ ) were recorded before and after each reaction.

The nanoscale morphologies of sulfided catalysts were observed using a highresolution transmission electron microscope (HRTEM, JEM-2010F, JEOL) at an acceleration voltage of $200 \mathrm{keV}$.

The acid sites of the catalysts were examined using pyridine FT-IR spectroscopy. The catalysts were pretreated at $450^{\circ} \mathrm{C}$ for $8 \mathrm{~h}$ under vacuum $\left(1 \times 10^{-4} \mathrm{~Pa}\right)$, and purified pyridine vapor was adsorbed at ambient temperatures for $30 \mathrm{~min}$. IR spectra of the remaining pyridine were collected at various temperatures. 


\section{Results and discussion}

\subsection{The analyses of catalysts}

The XRD profiles of catalysts are shown in Figure 1. The characteristic diffraction peaks of Mo oxide formed an active phase, and alumina and USY zeolite compositions from the support are marked in the figure. XRD peaks of $\mathrm{NiO}$ species were not detected, indicating that $\mathrm{NiO}$ species were finely distributed on the support surface. The characteristic diffraction peaks of $\gamma$-alumina appeared in all catalysts, although their intensities varied according to the amounts of coated alumina. Compared with the crystallinity of alumina-coated USY zeolite, the crystallinities of the supports were much strongly influenced by coating amounts. From XRD results, the relative amount of coated alumina in the as-received catalysts was quantified as:

$$
\text { NMACZ-1 > NMACZ-2(40) > NMACZ-2(20) > NMACZ-2(10) > NMACZ-2 }
$$

Other physical properties of the catalysts are summarized in Table 2. Surface area decreased with increasing amounts of coated alumina. NMACZ-2 had a higher surface area than NMACZ-1 because it had less coated alumina. NMAZ had the highest surface area of the seven catalysts because of the naked USY-zeolite in the support. 


\subsection{The evaluation of the reaction performances of catalysts}

Table 3 shows the distributions of product molecules after hydro-conversion of 1-methyl naphthalene at $360^{\circ} \mathrm{C}$ for $6 \mathrm{~h}$. The results of preliminary experiments using dodecane as a feed showed that most of the light hydrocarbons generated during reaction with 1-methyl naphthalene resulted from dodecane cracking. Furthermore, the production of hydrocarbons from dodecane was significantly inhibited by the presence of 1-methyl naphthalene in the feed, because it is much more nucleophilic than dodecane towards both Brönsted acid and metal sites. Thus, the low molecular weight products derived exclusively from dodecane cracking were not included in the calculation of the product distributions from the hydro-conversions of 1-methyl naphthalene over all catalysts. The reactivity was estimated as a concentration ratio between each of products measured experimentally and the product predicted for complete hydro-conversion of 1-methyl naphthalene. The accuracy of GC-AED analysis was not high enough in most cases. The mass balances of the reactions had deviations of $\pm 3 \%$, except for the case of NMACZ-1, which was $\pm 5 \%$. However, they are shown without any correction.

We assumed 1-methyl naphthalene isomerized to 2-methyl naphthalene on the $\gamma$-alumina, ACZ series, and AZ-supported bimetal (Ni, Mo) catalysts based on product 
distributions of 6-methyl tetralin and 5-methyl tetralin. We also suggest that the isomerization between 5-methyl tetralin and 6-methyl tetralin was followed by HYD of 1-methyl naphthalene to 5-methyl tetralin.

The HYD of 1-methyl naphthalene to decalin species had tetralin intermediates using NMA as the catalyst. HYD of tetralin has been reported to take place not only on the metal centers but also on acid sites through hydrogen spillover from the metal surface. The decalin underwent a skeletal isomerization before the ring-opening and cracking reactions to (alkyl)cycloalkane. Small portions of the product $(12.41 \%$ of pentyl cyclohexane) resulted from the ring opening of decalin species due to cleavage of the corresponding carbonium ion as the Brönsted acid site attacked the $\mathrm{C}-\mathrm{C}$ bond of decalin.

The product distributions related to the ring opening of 1-methyl naphthalene were readily altered by the presence of coated alumina on the surface of USY zeolite. In particular, total (alkyl)benzene yields over NMACZ-2 improved with a minimum amount of coated alumina, even when the yields of total (alkyl)cycloalkane species decreased or were similar to those with much higher amounts of coated alumina. The activity improved due to an enhancement of surface acidity, which was supported by pyridine FT-IR and $\mathrm{NH}_{3}$-TPD data, as well as the characteristics of $\mathrm{MoS}_{2}$ stacks. 
Although NMAZ had naked acidic sites and higher surface acidity, the activity of ring-opening reactions of tetralin decreased slightly in comparison with NMACZ-2.

The lower activity was attributed to higher coverage of coke deposition over the naked acidic sites, compared with NMACZ-2, and the presence of dispersed bulk phase Mo oxide species on the alumina in the AZ support, which was confirmed by the shoulder peak at $998 \mathrm{~cm}^{-1}$ in Raman spectra [17].

Unlike noble metal catalysts, the loading of transition metals onto the zeolite increased the amount of Brönsted acid sites [7, 24, 25, 26]. However, the additional acid sites did not contribute to the catalyzed HC of tetralin species. Sato et al. [25, 27, 28] reported the $\mathrm{HC}$ of tetralin over bifunctional $\mathrm{NiW}$ sulfide catalysts supported on zeolites (USY, HY, and mordenite) under typical HC conditions of moderate temperature (623 K) and high hydrogen pressure $(6.1 \mathrm{MPa})$ with a low $\mathrm{H}_{2} /$ feed ratio. They showed that the ring opening of tetralin required relatively strong acid sites and was closely related to the hydrogen transfer capability of the supports, in the following order:

$$
\mathrm{NiW} / \mathrm{USY}>\mathrm{NiW} / \mathrm{HY}>\mathrm{NiW} / \mathrm{MOR}>\mathrm{NiW} / \mathrm{Al}_{2} \mathrm{O}_{3}
$$

Thus, moderate acidic sites derived with an optimum alumina coating on USYzeolite and higher hydrogen transfer capability of the support (USY zeolite) may result in a novel, effective support for the ring opening of tetralin species after the selective 
HYD of poly-aromatic compounds. 


\subsection{XPS analysis}

X-ray photoelectron spectra of all the calcined and sulfided catalysts were similar. The binding energies of oxide and sulfide catalysts are summarized in Table 4. Two distinguished peaks corresponding to the spin-splitting of $\mathrm{Mo}^{6+} 3 \mathrm{~d}_{5 / 2}$ (B.E. ca. 238 eV) and $\mathrm{Mo}^{6+} 3 \mathrm{~d}_{3 / 2}$ (B.E. ca. $242 \mathrm{eV}$ ) lines of Mo oxide species were assigned for the calcined catalysts. The two main peaks in the $\mathrm{Ni} 2 \mathrm{p}$ region were assigned to the spinsplitting of $\mathrm{Ni} 2 \mathrm{p}_{3 / 2}$ (B.E. $862 \mathrm{eV}$ ) and Ni 2p $\mathrm{p}_{1 / 2}$ (B.E. $880 \mathrm{eV}$ ), and the two broad peaks enveloped their corresponding shake-up lines. The Ni 2p XPS spectra suggested that the nickel species in the calcined catalyst could be assigned to $\mathrm{Ni}^{2+}$ in the interaction with the support and/or with Mo.

For the sulfided catalysts, the Mo 3d XPS spectra were separated into three sets of doublets, corresponding to $\mathrm{Mo}^{6+}, \mathrm{Mo}^{5+}$, and $\mathrm{Mo}^{4+}$ species. The $\mathrm{Mo}^{6+}$ species could have been $\mathrm{MoO}_{3}$ or another oxide phase that was not completely sulfided. The $\mathrm{Mo}^{5+}$ species could have been a Mo oxy-sulfided species $\left(\mathrm{MoOS}_{2}\right)$, and the $\mathrm{Mo}^{4+}$ species were $\mathrm{MoS}_{2}$ and Ni-Mo-S phases [29]. A broad peak at nearly $226 \mathrm{eV}$ was assigned to $\mathrm{S} 2 \mathrm{~s}$ [30]. The Ni $2 p_{3}$ XPS spectra showed a relatively intense peak near $853 \mathrm{eV}$, and a second band $(856 \mathrm{eV})$ partially overlapped the first one. The intense peaks of $\mathrm{Ni} 2 \mathrm{p}_{1}$ appeared at about $870 \mathrm{eV}$. The Ni sulfide species were assumed to be $\mathrm{Ni}_{3} \mathrm{~S}_{2}$, which 
suggests Ni-Mo-S was the active catalytic phase for the catalysis. The shape of the $\mathrm{Ni}$ $2 p$ enveloped with satellite peaks clearly showed the presence of non-sulfided $\mathrm{Ni}^{2+}$ species in all catalysts after sulfidation. The $\mathrm{Ni} 2 \mathrm{p}_{3}$ peak at about $856 \mathrm{eV}$ was also due to the presence of non-sulfided $\mathrm{Ni}^{2+}$ species [31]. The $\mathrm{Ni} 2 \mathrm{p}_{3}$ peak at nearly $853 \mathrm{eV}$, and the $\mathrm{S} 2 \mathrm{p}_{3}$ peak at $162 \mathrm{eV}$, were attributed to nickel sulfides [31, 32].

The S 2p spectra of all sulfided catalysts showed one peak with a binding energy $162 \mathrm{eV}$, which was assumed to be due to $\mathrm{S}^{2-}$ species [33]. No other signal was identified near B.E. $169 \mathrm{eV}$, indicating that no sulfate species existed and no oxidation of the catalysts occurred during the transfer of solid from the sulfiding reactor to the XPS chamber.

Similar binding energies for Mo and Ni species for all catalysts in the oxide state indicated that the support was not modified during the interaction between $\mathrm{Mo} / \mathrm{Ni}$ and the support, or between Mo and Ni at the surface. However, after sulfidation, the binding energies of $\mathrm{Mo}^{4+}, \mathrm{Ni} 2 \mathrm{p}_{3}$, and $\mathrm{S} 2 \mathrm{p}$ of NMACZ-1, NMACZ-2, and NMAZ were lower than those of NMA, indicating weaker interactions between $\mathrm{Mo} / \mathrm{Ni}$ and the supports or between Mo and Ni species. In particular, the weaker interaction between Mo and the support contributed to a higher reducibility that improved HC reactivity of the catalyst. 
The ratios of the intensities for each component of the XPS spectra (Table 5) were used to determine the surface species distribution. For oxide catalysts, the surface $\mathrm{Mo} / \mathrm{Ni}$ molar ratios were higher than the bulk Mo/Ni ratios, suggesting that more Mo species were distributed near the surfaces than inside the bulk. Previous studies showed Ni species were homogeneously distributed through the entire support, while Mo species were predominantly distributed in the vacancies near the surface of supports $(\gamma$ $\mathrm{Al}_{2} \mathrm{O}_{3}$ and alumina-coated zeolite) [34-36].

During sulfidation, both $\mathrm{Ni}$ and Mo species were redistributed. The surface $\mathrm{Mo} /(\mathrm{Al}+\mathrm{Si}), \mathrm{Ni} /(\mathrm{Al}+\mathrm{Si})$ and $\mathrm{Mo} / \mathrm{Ni}$ molar ratios dramatically decreased, suggesting that appreciable amounts of the surface Mo and Ni species migrated into the bulk. The Mo species had a greater reduction than the Ni species because of the change in alumina species or the amount coated on the surface.

The degree of sulfidation of the catalysts was estimated using the atomic ratio of $\mathrm{S} /(\mathrm{Mo}+\mathrm{Ni})$. From Table 5, NMACZ-2 had a higher ratio of $\mathrm{S} /(\mathrm{Mo}+\mathrm{Ni})$ than NMACZ-1, suggesting that the active phase with lower amounts of alumina-coated USY zeolite catalyst was more favorable for sulfidation. 


\subsection{HR-TEM of catalysts}

Representative TEM images of the four sulfided catalysts are shown in Figure 2. TEM images revealed typical layered structures of the $\mathrm{MoS}_{2}$ phase (confirmed by energy dispersive X-ray spectrometer, EDX). The average number of layers per slab was estimated by counting 250 crystallites (supporting data). Figure 3 shows results of the average number of $\mathrm{MoS}_{2}$ layers. In the Ni-Mo-S model, NiS was considered to be a source of promoter atoms and was located either at the edges in five-fold coordinated sites at (1010) edge planes of $\mathrm{MoS}_{2}$ or in the alumina lattice [37]. Because of their limited presence in catalysts and well dispersion, the NiS crystal size was too small to directly observe with TEM. The NMA catalyst had a much higher number of slab layers (4.47) and broader distributions compared to alumina-modified USY zeolite catalysts (NMACZ-1: 3.83, NMACZ-2: 3.76, NMAZ: 3.85). MoS slab distributions over alumina-coated USY zeolite were closely related to the surface Si and Al distributions (confirmed by XPS), although the sulfidation of calcined catalysts may lead to the redistribution of surface species. Compared with zeolites with various amounts of coated alumina, the less-coated NMACZ-2 showed a slightly lower number of average slab layers with a large weight of $30 \%$ for two layers. Such two-layered stacks were attributed to the zeolite supports and possibly changed the reactivity over the catalyst. 
However, despite the higher value of $\mathrm{Si} / \mathrm{Al}$ and similar weight of two-layered stacks in NMACZ-2, NMAZ showed a higher average slab number, which was attributed to the bulk phase Mo species on the alumina in AZ (physical mixture of USY zeolite and alumina). NMAZ had slab layer numbers of 9, 11, and 12, similar to NMA. From these results, it was concluded that $\mathrm{HC}$ reactivity was affected by the number of layered stacks of the active phase $\left(\mathrm{MoS}_{2}\right)$ and its distribution. A higher portion of least-layered stacks, especially two layers and below, might be an important factor for higher HC reactivity. That is, the alumina-coated surface may affect the number of layers, the MoS distribution and the reactivities of HYD and $\mathrm{HC}$. 


\subsection{Pyridine FT-IR}

Catalyst acidity is one of the key factors influencing HYD and HC in ringopening reactions to increase the cetane number and yield of products. Figure 4 shows the infrared spectra (FT-IR) of pyridine adsorbed on the alumina-coated zeolite catalysts that were evacuated at $30^{\circ} \mathrm{C}, 150^{\circ} \mathrm{C}$, and $300^{\circ} \mathrm{C}$ under $10^{-4}$ Torr after pyridine adsorption. Results are quantitatively summarized in Table 6. Similar signals were observed in the spectra in the range from 1400 to $1700 \mathrm{~cm}^{-1}$. Characteristic bands at 1446 and $1621 \mathrm{~cm}^{-1}$ were assigned to Lewis-bound pyridine, and bands at 1546 and $1639 \mathrm{~cm}^{-1}$ were assigned to the vibration of the pyridinium ion ring from pyridine bound to Brönsted acid sites [38, 39]. Another band at $1492 \mathrm{~cm}^{-1}$ was assigned to pyridine associated with both Brönsted and Lewis sites. The amounts of Brönsted and Lewis acid sites in NMACZ-2 were much higher (about 30\%) than those in NMACZ-1 catalysts, which could have been due to the naked zeolite surface or lower amounts of coated alumina confirmed by $\mathrm{Si} / \mathrm{Al}$ values from XPS data. Similar behavior in $\mathrm{NH}_{3}$ TPD was observed in previous work [17]. Increased pyridine desorption temperature reduced both types of acid sites. In the case of NMACZ-1, degradation was accompanied by a reduction in Brönsted and Lewis acid sites, of $57 \%$ and $72 \%$, respectively, compared with the initial and final desorption temperatures, while 
reductions in NMACZ-2 were smaller ( $31 \%$ and 53\%, respectively). The higher acid strength in NMACZ-2, compared with NMACZ-1, was supported by strongly chemisorbed pyridinium over the zeolite surface, which improved the $\mathrm{HC}$ reactivity.

The additives to alumina, such as silica, zeolite, binary oxide and phosphates, were reported to be effective because of increased acidity [40]. In particular, Y-type zeolites used as acidic substrates enhanced the acidity by contact with the alumina surface, although they are not necessarily highly acidic by themselves. On the other hand, the acidic surface may suffer accelerated coke formation from the cracking of hydrocarbons into light hydrocarbons, which can deactivate the catalyst. The lower HC reactivity of NMAZ, compared with NMACZ-2, was attributed to acceleration of coke formation over its naked acidic surface. Such disadvantages can be mitigated by optimizing the acidity through reduced direct contact between the acidic surface and the feed, as well as by placing NiMoS in the vicinity of the acidic sites can hydrogenate the adsorbed species. Thus, NMACZ-2 with moderate acidic sites should be the most suitable for $\mathrm{HC}$ reactions, which can minimize coking and deactivation. 


\section{Conclusion}

Influences on the reactivities of HYD and HC were examined using $\gamma$-aluminaand alumina-modified zeolite (NMACZ series and NMAZ)-supported NiMo catalysts.

HYD and HC reactions over the catalysts were strongly dependent on the interaction between Mo and support materials. NMA was favorable for HYD reactions, whereas the NMACZ series and NMAZ were favorable for $\mathrm{HC}$ reactions, because of weaker interactions between Mo and ACZ/AZ supports, indicating higher reducibility.

The surface containing coated alumina affected the slab layer number and distribution of $\mathrm{MoS}_{2}$ and altered the reactivities of HYD and HC. Unlike Al-rich surfaces over catalysts such as NMA, NMAZ and NMACZ-1, a higher weight percent of least-layered stacks, especially two layers, was characteristic of NMACZ-2, which led to higher $\mathrm{HC}$ reactivity.

NMACZ-2 with the minimum amount of alumina-coated USY-zeolite showed enhanced activity for the ring opening of tetralin species because of the acidic properties of the support. From the pyridine-FTIR data, the stronger acidity of NMACZ-2, compared with NMACZ-1, was confirmed by strongly chemisorbed pyridinium over the coated zeolite surface. Additionally, moderated acid sites over NMACZ-2 with an optimum alumina coating minimized coking and deactivation, compared with NMAZ. 
Thus, NMACZ-2 was the most suitable for HC reactions. 


\section{Appendix (Nomenclature)}

\section{List of Abbreviations}

\section{Chemicals}

(Alkyl)benzenes: Benzene or alkyl substituted benzene

LCO: Light cycle oil

\section{Catalysts}

USY: Ultra stable Y zeolite (Si/Al of zeolite: 30$)$

ASA: Amorphous silica-alumina

NMA: Ni-Mo supported on $\gamma$-alumina

NMAZ: Ni-Mo supported on a physical mixture of alumina and USY zeolite (AZ)

NMACZ: Ni-Mo supported on alumina-coated USY zeolite (ACZ)

\section{Reactions}

HYD: Hydrogenation

HC: Hydrocracking

HDS: Hydrodesulfurization

HDN: Hydrodenitrogenation 


\section{Acknowledgements}

This work was carried out under the financial support of JCCP within the cooperation agreement between Japan and Saudi Arabia. This work was also carried out within the

framework of the Global-Center of Excellence (G-COE) of Novel Carbon Resource Sciences at Kyushu University. 


\section{References}

[1] Bouchy M, Peureux-Denys S, Dufresne P, Kasztelan S. Hydrogenation of hydrocracking of a model light cycle oil feed. 2. Properties of a sulfided NiMo hydrocracking catalyst. Ind Eng Chem Res 1993;32:1592-602

[2] Stannislaus A, Cooper BH. Aromatic hydrogenation catalysis: A review. Catal RevSci Eng 1994;36(1):75-123

[3] Li W, Wang Z, Zhang M, Tao K. Novel $\mathrm{Ni}_{2} \mathrm{Mo}_{3} \mathrm{~N} /$ zeolite catalysts used for aromatics hydrogenation as well as polycyclic hydrocarbon ring opening. Catal Comm 2005;6:656-60

[4] Chareonpanic M, Tomita A. Selective production of BTX by hydrocracking of coal volatile matter over zeolite catalyst. Energy Fuel 1994;8:1522-3

[5] Chareonpanich M, Zhang Z, Tomita A. Hydrocracking of aromatic hydrocarbons over USY-Zeolite. Energy Fuel 1996;10:927-31

[6] Corma A, Martinez A, Martinez-Soria V. Catalytic performance of new delaminated ITQ-2 zeolite for mild hydrocracking and aromatic hydrogenation processes. J Catal 2001;200:259-69

[7] Corma A, Gonzalez-Alfaro V, Orchilles AV. Decalin and tetralin as probe molecules for cracking and hydrotreating the light cycle oil. J Catal 2001;200:34-43 
[8] Liu X, Smith KJ. Acidity and deactivation of $\mathrm{MO}_{2} \mathrm{C} / \mathrm{HY}$ catalysts used for the hydrogenation and ring opening of naphthalene. Appl Catal A 2008;335:230-40

[9] Linares CF, Ameaqueta P, Scott C. Mo/MCM-41-Type mesoporous materials doubly promoted with Fe and Ni for hydrotreating reaction. Fuel 2008;87:2817-23

[10] Corma A, Martinez A, Martinez-Soria V, Monton JB. Hydrocracking of vacuum gasoil on novel mesoporous MCM-41 aluminosilicate catalyst. J Catal 1995;153:25-31

[11] Reddy KM, Wei B, Song C. Mesoporous molecular sieve MCM-41 supported CoMo catalyst for hydrodesulfurization of petroleum residues. Catal Today 1998;43:26172

[12] Song C, Reddy KM. Mesoporous molecular sieve MCM-41 supported Co-Mo catalyst for hydrodesulfurization of dibenzothiophene in distillate fuels. Appl Catal A: $1999 ; 176: 1-10$

[13] Ramirez J, Contreras R, Castillo P, Klimova T. Characterization and catalytic activity of CoMo HDS catalysts supported on alumina-MCM-41. Appl Catal A 2001;197:69-78

[14] Sano Y, Sugahara K, Choi k, Korai Y, Mochida I. Two-step adsorption process for deep desulfurization of diesel oil. Fuel 2005;84:903-10

[15] Murti SDS, Choi K, Sakanishi K, Okuma O, Korai Y, Mochida Isao. Analysis and 
removal of heteroatom containing species in coal liquid distillate over NiMo catalysts. Fuel 2005;84:135-42

[16] Murti SDS, Choi K, Korai Y, Mochida I. Performance of spent sulfide catalysts in hydrosulfurization of straight run and nitrogen-removed gas oil. Appl Catal A 2005;280:133-9

[17] Kunisada N, Choi k, Korai Y, Mochida I, Nakano K. Contrast activities of four alumina-silica-supported nickel-molybdenum sulfide catalysts for deep desulfurization of gas oil. Appl Catal A 2005;279:235-9

[18] Kunisada N, Choi k, Korai Y, Mochida I, Nakano K. Optimum coating of USY as a support component of NiMoS on alumina for deep HDS of gas oil. Appl Catal A $2004 ; 276: 51-9$

[19] Choi k, Sano Y, Korai Y, Mochida I. An approach to the deep hydrodesulfurization of light cycle oil. Appl Catal B 2004;53:275-83

[20] Kunisada N, Choi k, Korai Y, Mochida I, Nakano K. Optimization of silica content in alumina-silica support for NiMo sulfide to achieve deep desulfurization of gas oil. Applied Catalysis A 2004;273:287-94

[21] Choi k, Korai Y, Mochida I, Ryu J, Min W. Impact of removal extent of nitrogen in gas oil on its HDS performance: an efficient approach to its ultra deep desulfurization. 
Applied Catalysis B 2004;50:9-16

[22] Stee LLV, Brinkman UAT. Gas chromatography with atomic emission detection: a powerful technique. Trends Anal Chem 2002;21:618-26

[23] Gurka DF, Pyle S, Titus R. Environmental applications of gas chromatography/atomic emission detection. Anal Chem 1997;69:2411-17

[24] Santikunaporn M, Herrera JE, Jongpatiwut S, Resasco DE, Alvarez WE, Sughrue EL. Ring opening of decalin and tetralin on $\mathrm{HY}$ and Pt/HY Zeolite catalysts. J Catal 2004;280:100-13

[25] Sato K, Iwata Y, Yoneda T, Nishijima A, Miki Y, Shimada H. Hydrocracking of diphenylmethane and tetralin over bifunctional NiW sulfide catalysts supported on three of zeolites. Catal Today 1998;45:367-74

[26] Li D, Nishijima A, Morris DE. Zeolite-supported Ni and Mo catalysts for hydrotreatments. J Catal 1999;182:339-48

[27] Sato K, Iwata Y, Miki Y, Shimada H. Hydrocracking of tetralin over NiW/USY zeolite catalysts: For the improvement of heavy-oil upgrading catalysts. J Catal $1999 ; 186: 45-56$

[28] Sato K, Nishijima A, Honna K, Matsubayashi N, Shimada H. Role of HY zeolite mesopores in hydrocracking of heavy oils. J Catal 2001;200:288-297 
[29] Li D, Imamura M, Shimada H, Nishijima A. Spectroscopic Characterization of Ni$\mathrm{Mo} / \gamma-\mathrm{Al}_{2} \mathrm{O}_{3}-\mathrm{B}_{2} \mathrm{O}_{3}$ catalysts for hydrodesulfurization of dibenzothiophene. $\mathrm{J}$ Catal $1997 ; 170: 357-65$

[30] Li D, Nishijima A, Morris DE, Guthrie GD. Activity and Structure of hydrotreating Ni-Mo sulfide catalysts supported on $\gamma-\mathrm{Al}_{2} \mathrm{O}_{3}$-USY zeolite. J Catal 1999;188:111-24

[31] Pawelec B, Daza L, Fierro JLG, Anderson JA. Regeneration of Ni-USY catalysts used in benzene hydrogenation. Appl Catal A 1996;145:307-22

[32] Shalvoy RB, Reucroft PJ, J Vac Sci Technol 1979;16:567-9

[33] Bendezu S, Cid R, Fierro JLG, Lopez Agudo A. Thiophene hydrodesulfurization on sulfide Ni, W and NiW/USY zeolite catalysts: effect of the preparation method. Appl Catal A 2000;197:47-60

[34] Vordonis L, Spanos N, Koutsoukos PG, Lycourghiotis A. Mechanism of adsorption of $\mathrm{Co}^{2+}$ and $\mathrm{Ni}^{2+}$ ions on the "Pure and Fluorinated $\gamma$-Alumina/Electrolyte Solution" Interface. Langmuir 1992;8:1736-43

[35] Spanos N, Lycourghiotis A. Codeposition of $\mathrm{Mo}^{(\mathrm{VI})}$ species and $\mathrm{Ni}^{2+}$ ions on the $\gamma$ alumina surface: mechanistic model. J Colloid Interface Sci 1995;171:306-318

[36] Spanos N, Lycourghiotis A. Molybdenum-oxo species deposited on alumina by adsorption. J Catal 1994;147:57-71 
[37] Topsoe H, Clausen BS, Massoth FE. A reviw: "Hydrotreating Catalysis Science and Technology”. Springer-Verlag. New York; 1996

[38] Kataoka T, Dumesic JA. Acidity of unsupported and silica-supported vanadia, molybdena and titania as studied by pyridine adsorption. J Catal1998;112:66-79 [39] Chakraborty B, Viswanathan B. Surface acidity of MCM-41 by in situ IR studies of pyridine adsorption. Catal Today 1999;49:253-60

[40] B.-C. Kang, S.-T. Wu, H.-H. Tsai, J.-C. Wu, Appl Catal A 1988;45; 221-238 
Table 1. Chromatographic conditions for C-species analysis

\begin{tabular}{|c|c|}
\hline \multicolumn{2}{|l|}{ GC-AED } \\
\hline Inlet volume $(\mu \ell)$ & 1 \\
\hline Inlet mode & Split \\
\hline Split ratio & 10 \\
\hline Inlet temp. $\left({ }^{\circ} \mathrm{C}\right)$ & 280 \\
\hline Inlet pressure (psi) & 11.8 \\
\hline Oven temp. $\left({ }^{\circ} \mathrm{C}\right)$ & $35^{\circ} \mathrm{C} \sim 114^{\circ} \mathrm{C}\left(1^{\circ} \mathrm{C} / \mathrm{min}\right) \sim 320^{\circ} \mathrm{C}\left(1.7^{\circ} \mathrm{C} / \mathrm{min}\right)$ \\
\hline Transfer line temp. $\left({ }^{\circ} \mathrm{C}\right)$ & 350 \\
\hline Cavity temp. $\left({ }^{\circ} \mathrm{C}\right)$ & 350 \\
\hline $\mathrm{H}_{2}$ reagent $(\mathrm{psi})$ & 40 \\
\hline $\mathrm{O}_{2}$ reagent $(\mathrm{psi})$ & 80 \\
\hline $\mathrm{CH}_{4}$ reagent (psi) & 50 \\
\hline Makeup gas (ml/min) & 230 \\
\hline Wave length (nm) & 179 \\
\hline \multicolumn{2}{|l|}{ GC-MS } \\
\hline Inlet volume $(\mu \ell)$ & 3 \\
\hline Inlet mode & Splitless \\
\hline Inlet temp. $\left({ }^{\circ} \mathrm{C}\right)$ & $280^{\circ} \mathrm{C}$ \\
\hline Inlet pressure (psi) & 11.3 \\
\hline Oven temp. $\left({ }^{\circ} \mathrm{C}\right)$ & $35^{\circ} \mathrm{C} \sim 114^{\circ} \mathrm{C}\left(1^{\circ} \mathrm{C} / \mathrm{min}\right) \sim 320^{\circ} \mathrm{C}\left(1.7^{\circ} \mathrm{C} / \mathrm{min}\right)$ \\
\hline
\end{tabular}

* The same HP-1MS column was used in GC-AED and GC-MS. 
Table 2. Physical properties of the oxide catalysts

\begin{tabular}{cccc}
\hline Catalysts & $\begin{array}{c}\text { BET surface } \\
\text { area } \\
\left(\mathrm{m}^{2} / \mathrm{g}\right)\end{array}$ & $\begin{array}{c}\text { Total pore } \\
\text { volume } \\
\left(\mathrm{cm}^{3} / \mathrm{g}\right)\end{array}$ & $\begin{array}{c}\text { Avg. pore } \\
\text { diameter } \\
(\AA)\end{array}$ \\
\hline NMA & 128.9 & 0.46 & 11.7 \\
NMACZ-1 & 131.5 & 0.48 & 6.7 \\
NMACZ-2(40) & 155.1 & 0.43 & 7.2 \\
NMACZ-2(20) & 201.9 & 0.41 & 7.7 \\
NMACZ-2(10) & 242.4 & 0.41 & 7.2 \\
NMACZ-2 & 265.1 & 0.48 & 6.7 \\
NMAZ & 341.6 & 0.48 & 6.7 \\
\hline
\end{tabular}


Table 3. Reactivity of hydroconversion over all catalysts (after $6 \mathrm{~h}$ reaction time, mol\%)

\begin{tabular}{|c|c|c|c|c|c|c|c|}
\hline Products & NMA & NMACZ-1 & $\begin{array}{c}\text { NMACZ-2 } \\
(40)\end{array}$ & $\begin{array}{c}\text { NMACZ-2 } \\
\text { (20) }\end{array}$ & $\begin{array}{c}\text { NMACZ-2 } \\
\text { (10) }\end{array}$ & NMACZ-2 & NMAZ \\
\hline Pentyl cyclohexane & 12.41 & 18.21 & 25.34 & 4.10 & - & - & - \\
\hline 1-methyl cyclohexane & - & 0.71 & 1.89 & 7.00 & 9.55 & 5.67 & 8.27 \\
\hline Cyclopentane & - & 0.70 & 1.17 & - & - & - & - \\
\hline $\begin{array}{l}\text { 1,3-dimethyl } \\
\text { cyclopentane }\end{array}$ & - & - & - & 4.13 & 5.62 & 8.24 & 4.76 \\
\hline $\begin{array}{l}\text { 1,2-dimethyl } \\
\text { cyclopentane }\end{array}$ & - & - & - & 6.69 & 8.30 & 7.86 & 5.63 \\
\hline $\begin{array}{c}\text { Total } \\
\text { alkyl cycloalkane }\end{array}$ & 12.41 & 19.62 & 28.4 & 21.92 & 23.37 & 21.77 & 18.63 \\
\hline Cis-2-methyl decalin & 5.35 & 4.26 & 4.07 & - & - & - & - \\
\hline 2-methyl decalin & 15.04 & 16.04 & 11.21 & - & - & - & - \\
\hline Trans-2-methyl decalin & 23.89 & 20.67 & 19.89 & 4.96 & - & - & - \\
\hline Cis-decalin & 10.56 & 6.45 & 5.17 & 3.85 & - & - & - \\
\hline Cis-1-methyl decalin & 20.61 & 15.21 & 13.48 & 11.10 & - & - & - \\
\hline 6-methyl tetralin & 5.53 & 6.52 & 4.27 & 0.90 & 3.14 & 0.05 & 0.49 \\
\hline 5-methyl tetralin & 7.24 & 4.13 & 2.35 & 1.53 & 2.89 & 0.22 & 1.23 \\
\hline $\begin{array}{c}\text { Total } \\
\text { Tetralin/decalin }\end{array}$ & 88.71 & 73.28 & 60.44 & 22.34 & 6.03 & 0.27 & 1.72 \\
\hline Benzene & - & 0.18 & 0.38 & 3.27 & 4.79 & 7.81 & 6.86 \\
\hline Toluene & - & 0.24 & 0.40 & 1.60 & 3.60 & 2.63 & 2.03 \\
\hline Ethyl-benzene & - & 0.51 & 1.77 & 11.26 & 13.88 & 17.26 & 14.33 \\
\hline P-xylene & - & 0.59 & 2.09 & 11.36 & 13.95 & 16.90 & 14.89 \\
\hline Alkyl-benzenes $^{a}$ & - & & 4.67 & 22.92 & 27.45 & 35.32 & 35.00 \\
\hline Total (alkyl)benzene & $\mathbf{0}$ & 1.52 & 9.31 & 50.41 & 63.67 & 79.92 & 73.11 \\
\hline 1-methyl napththalene & 1.70 & 1.17 & 0.92 & 4.78 & 4.49 & 0.16 & 4.49 \\
\hline \multicolumn{8}{|c|}{$a$ : 1-ethyl-3-methyl benzene } \\
\hline \multicolumn{8}{|c|}{ 1-ethyl-4-methyl benzene } \\
\hline \multicolumn{8}{|c|}{ 1,3,5-trimethyl benzene } \\
\hline \multicolumn{8}{|c|}{ 1-ethy-2methyl benzene } \\
\hline \multicolumn{8}{|c|}{ 1,2,3-trimethyl benzene } \\
\hline \multicolumn{8}{|c|}{ 1,2,4-trimethyl benzene } \\
\hline \multicolumn{8}{|c|}{ 1-ethyl-2,3-dimethyl benzene } \\
\hline 1,3-dimet & enzen & & & & & & \\
\hline
\end{tabular}


Table 4. The binding energies (eV) of oxidic and sulfide catalysts in XPS

\begin{tabular}{|c|c|c|c|c|c|c|c|c|}
\hline & \multicolumn{2}{|c|}{ NMA } & \multicolumn{2}{|c|}{ NMACZ-1 } & \multicolumn{2}{|c|}{ NMACZ-2 } & \multicolumn{2}{|c|}{ NMAZ } \\
\hline & Oxide & Sulfide & Oxide & Sulfide & Oxide & Sulfide & Oxide & Sulfide \\
\hline $\operatorname{Mo~3d_{3}(M^{6+})}$ & 242.14 & \multirow{2}{*}{-} & 241.79 & \multirow{2}{*}{ - } & 241.95 & \multirow{2}{*}{-} & 241.66 & \multirow{2}{*}{ - } \\
\hline $\operatorname{Mo~} 3 d_{5}\left(M^{6+}\right)$ & 238.90 & & 238.51 & & 238.73 & & 238.40 & \\
\hline $\mathrm{Mo}^{6+}$ & \multirow{3}{*}{ - } & 233.41 & \multirow{3}{*}{-} & 232.78 & & 232.95 & \multirow{3}{*}{-} & 232.29 \\
\hline $\mathrm{Mo}^{5+}(\mathrm{Oxy}$-sulfide $)$ & & 234.06 & & 233.82 & - & 233.70 & & 233.69 \\
\hline $\mathrm{Mo}^{4+}\left(\mathrm{MoS}_{2}\right)$ & & 229.11 & & 228.80 & & 228.90 & & 228.68 \\
\hline Ni $2 p_{1}$ & 880.20 & \multirow{2}{*}{ - } & 880.17 & - & 879.76 & - & \multirow{2}{*}{\multicolumn{2}{|c|}{$\begin{array}{l}879.99 \\
862.71\end{array}$}} \\
\hline Ni $2 p_{3}$ & 862.72 & & 862.59 & & 862.55 & & & \\
\hline Ni $2 p_{1}(\mathrm{NiO})$ & \multirow{4}{*}{-} & 874.33 & \multirow{4}{*}{-} & 874.23 & \multirow{4}{*}{-} & 874.16 & \multirow{4}{*}{ - } & 877.46 \\
\hline Ni $2 p_{1}$ (disulfide) & & 870.09 & & 870.39 & & 869.75 & & 869.57 \\
\hline $\mathrm{Ni} 2 \mathrm{p}_{3}$ (NiO) & & 856.57 & & 856.52 & & 856.47 & & 856.24 \\
\hline Ni $2 p_{3}$ (disulfide) & & 853.37 & & 853.33 & & 853.25 & & 853.25 \\
\hline S 2s & & 226.15 & & 226.43 & & 225.85 & & 226.99 \\
\hline $\mathbf{S} 2 \mathbf{p}_{1}$ & - & 161.99 & - & 161.48 & - & 161.58 & - & 161.57 \\
\hline $\mathbf{S} 2 \mathbf{p}_{3}$ & & 163.12 & & 162.54 & & 162.91 & & 162.80 \\
\hline
\end{tabular}


Table 5. Surface species distribution calculated form XPS

\begin{tabular}{|c|c|c|c|c|c|c|c|c|}
\hline & \multicolumn{2}{|c|}{ NMA } & \multicolumn{2}{|c|}{ NMACZ-1 } & \multicolumn{2}{|c|}{ NMACZ-2 } & \multicolumn{2}{|c|}{ NMAZ } \\
\hline & Oxide & Sulfide & Oxide & Sulfide & Oxide & Sulfide & Oxide & Sulfide \\
\hline $\begin{array}{c}\text { Bulk } \\
\text { Mo/Ni }\end{array}$ & 1.62 & & 1.62 & & 1.63 & & 1.62 & \\
\hline $\mathrm{Mo} /(\mathrm{Al}+\mathrm{Si})$ & 0.65 & 0.19 & 0.67 & 0.21 & 0.69 & 0.21 & 0.72 & 0.24 \\
\hline $\mathrm{Ni} /(\mathbf{A l + S i})$ & 0.34 & 0.21 & 0.32 & 0.23 & 0.32 & 0.26 & 0.34 & 0.29 \\
\hline Mo/Ni & 1.90 & 0.91 & 2.09 & 0.73 & 2.13 & 0.81 & 2.11 & 0.82 \\
\hline Si/Al & - & - & 0.11 & 0.13 & 0.25 & 0.31 & 0.31 & 0.36 \\
\hline $\mathrm{S} /(\mathbf{M o}+\mathbf{N i})$ & - & 0.21 & - & 0.17 & - & 0.20 & - & 0.22 \\
\hline
\end{tabular}


Table 6. Surface acidity of Al coated zeolite determined by pyridine FT-IR and $\mathrm{NH}_{3}$-TPD

\begin{tabular}{|c|c|c|c|c|c|c|c|}
\hline \multirow{2}{*}{ Samples } & \multicolumn{3}{|c|}{$\begin{array}{c}\text { Brönsted }^{a} \\
(\mathbf{P y}-\mu \text { mol/g cat. })\end{array}$} & \multicolumn{3}{|c|}{ 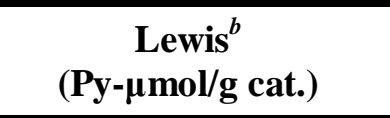 } & \multirow{2}{*}{$\begin{array}{c}\mathrm{NH}_{3}{ }^{c} \\
\text { ( } \mu \mathrm{mol} / \mathrm{g} \text { cat. })\end{array}$} \\
\hline & $30^{\circ} \mathrm{C}$ & $150^{\circ} \mathrm{C}$ & $300^{\circ} \mathrm{C}$ & $30^{\circ} \mathrm{C}$ & $150^{\circ} \mathrm{C}$ & $300^{\circ} \mathrm{C}$ & \\
\hline NMACZ-1 & 330.5 & 196.9 & 142.4 & 771.5 & 390.6 & 216.5 & 610 \\
\hline NMACZ-2 & 501.2 & 433.1 & 346.4 & 1007.3 & 671.4 & 469.9 & 790 \\
\hline
\end{tabular}
${ }^{a}: 1.88 \mathrm{IA}(\mathrm{B}) \mathrm{R}^{2} / \mathrm{W}$
${ }^{b}: 1.42 \mathrm{IA}(\mathrm{L}) \mathrm{R}^{2} / \mathrm{W}$
${ }^{c}:$ reference [17]

Here, IA: Integrated absorbance

$\mathrm{R}$ : Disk radius

$\mathrm{W}$ : Weight of disk 


\section{Illustrations}

Figure 1. XRD profiles of alumina and/or USY zeolite supported NiMo catalysts:

(a) NMA, (b) NMACZ-1, (c) NMACZ-2(40), (d) NMACZ-2(20),

(e) NMACZ-2(10), (f) NMACZ-2, (g) NMAZ

Figure 2. The representative TEM images: (A) NMA, (B) NMACZ-1, (C) NMACZ-2, (D)NMAZ

Figure 3. The slab number distributions for the sulfided catalysts: (a) NMA, (b) NMACZ-1, (c) NMACZ-2, (d) NMAZ

Figure 4. Infrared spectra of pyridine adsorbed on the different Al coating amounted zeolite catalysts at various desorption temperature: (a) NMACZ-1, (b)NMACZ-2 


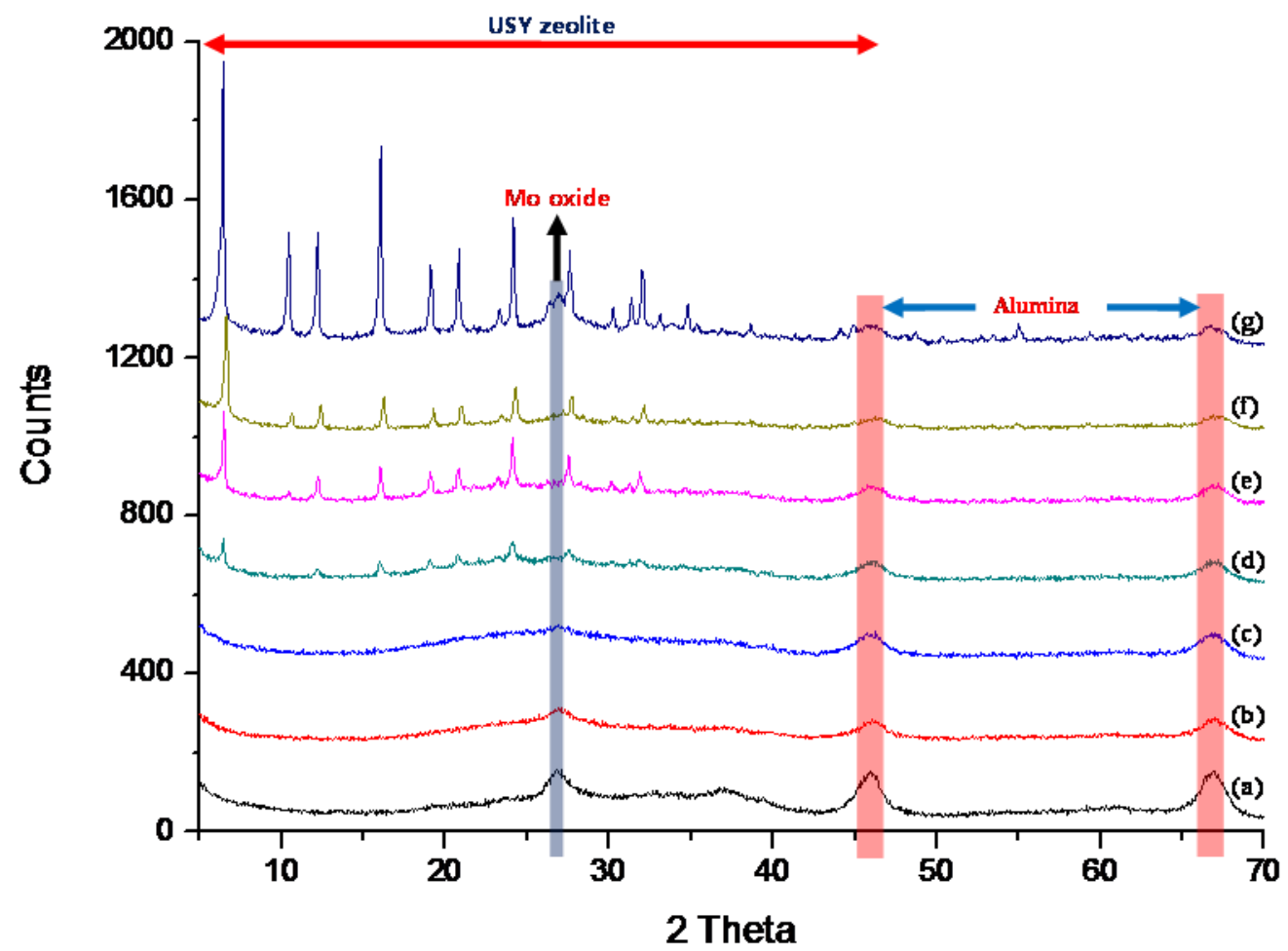

Figure 1. XRD profiles of alumina and/or USY zeolite supported NiMo catalysts:

(a) NMA, (b) NMACZ-1, (c) NMACZ-2(40), (d) NMACZ-2(20),

(e) NMACZ-2(10), (f) NMACZ-2, (g) NMAZ 

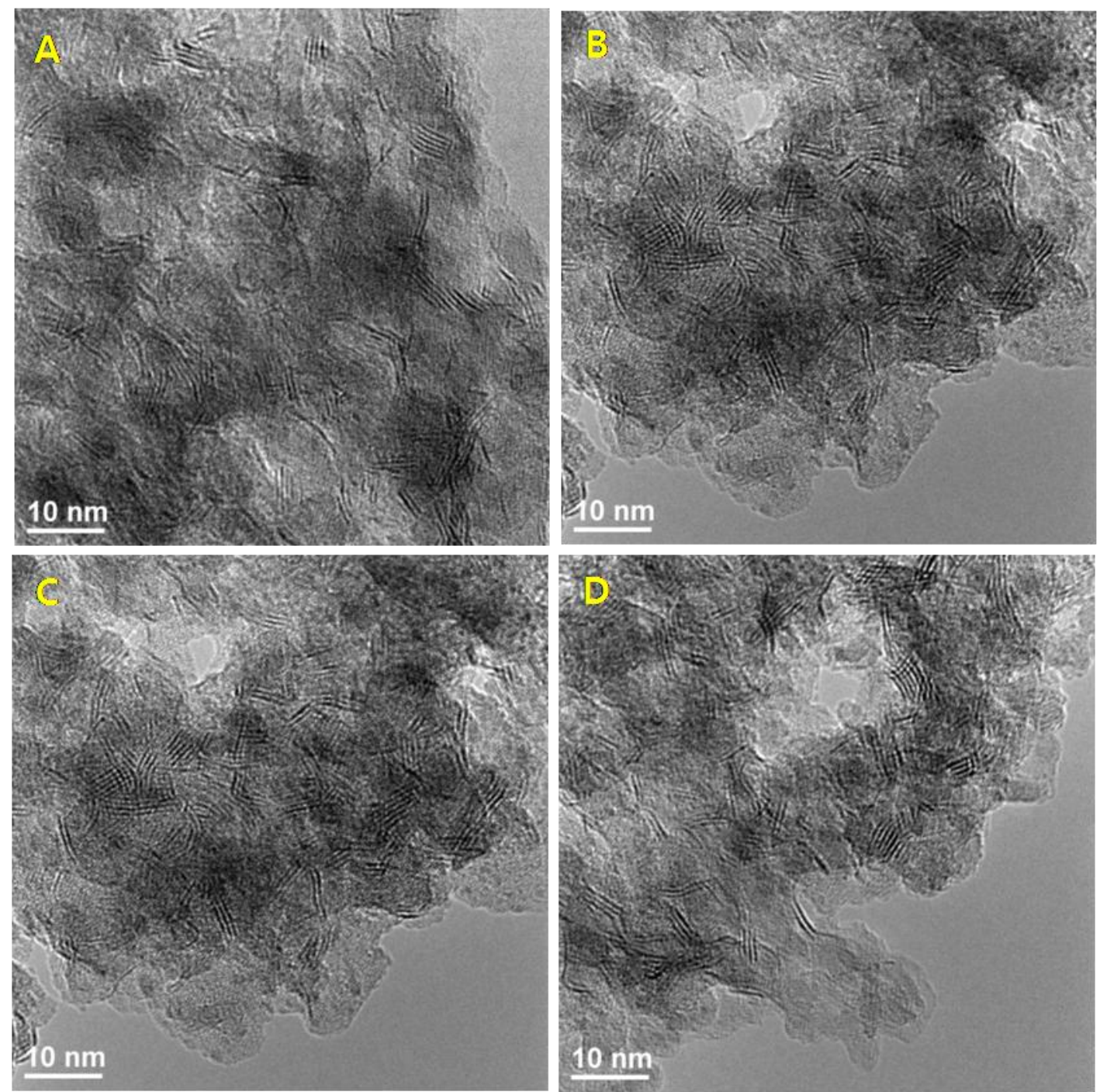

Figure 2. The representative TEM images: (A) NMA, (B) NMACZ-1, (C) NMACZ-2, (D)NMAZ 


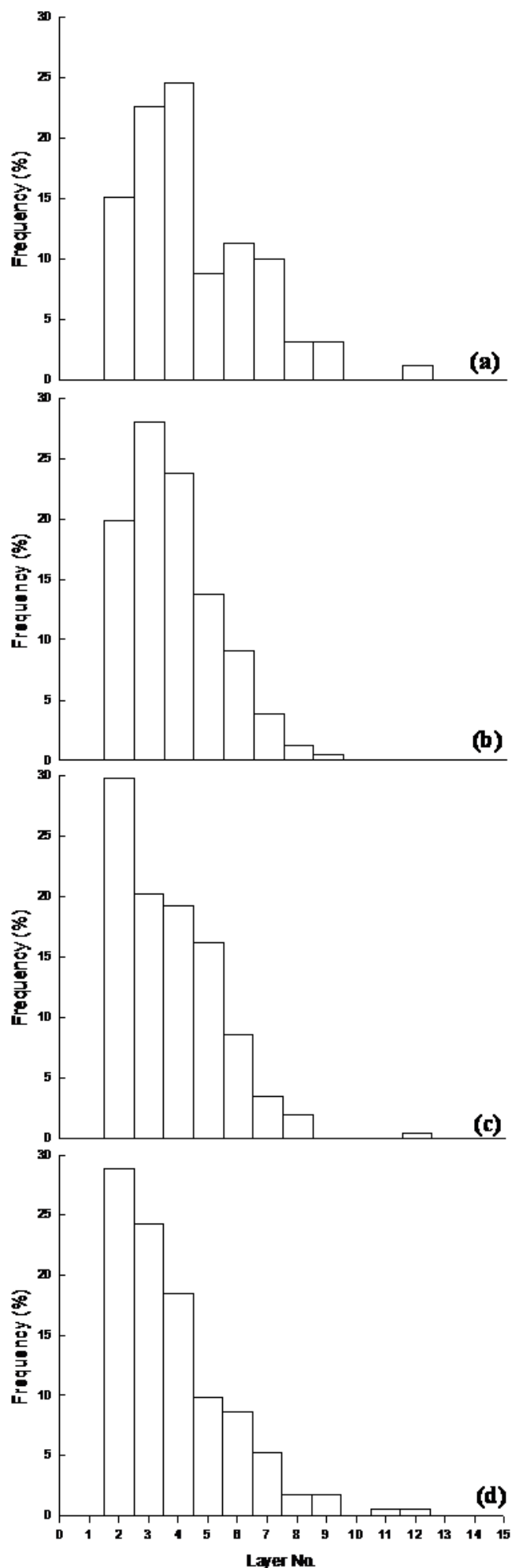

Figure 3. The slab number distributions for the sulfided catalysts: (a) NMA, (b) NMACZ-1, (c) NMACZ-2, (d) NMAZ 


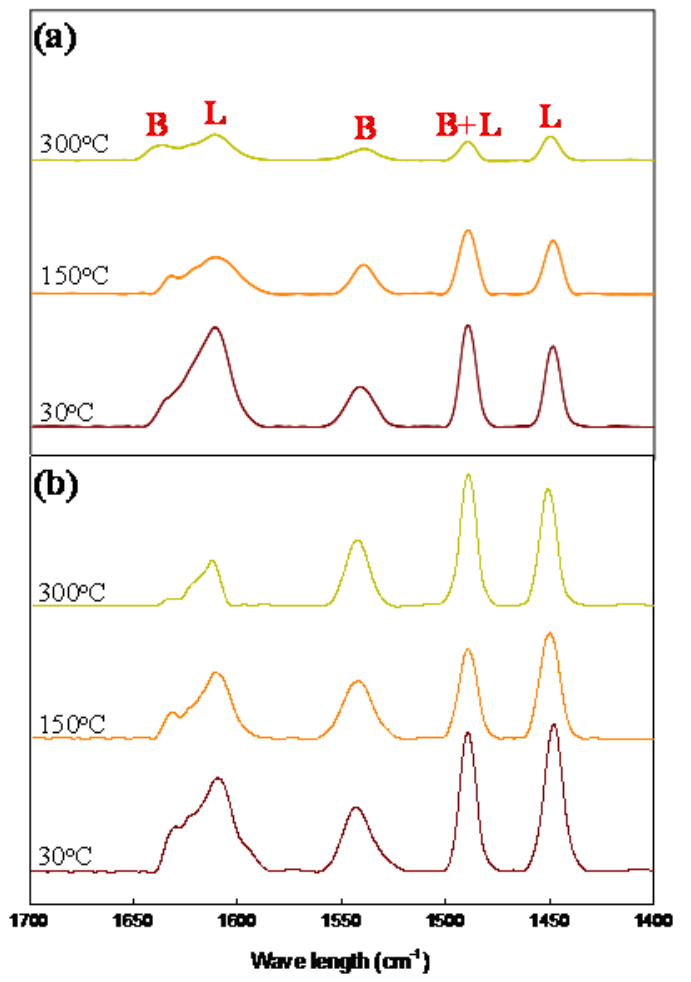

Figure 4. Infrared spectra of pyridine adsorbed on the different Al coating amounted zeolite catalysts at various desorption temperature: (a) NMACZ-1, (b)NMACZ-2 